\title{
Relação entre a violência e a saúde mental das mulheres no Brasil: análise das políticas públicas
}

\section{The relationship between violence and mental health of women in Brazil: an analysis of public policies}

\section{Relación entre la violencia y la salud mental de las mujeres en Brasil: análisis de las políticas públicas}

\author{
Mariana Pedrosa de Medeiros* \\ Universidade de Brasília - UnB, Brasília, Distrito Federal, Brasil \\ Valeska Zanello** \\ Universidade de Brasília - UnB, Brasília, Distrito Federal, Brasil
}

\begin{abstract}
RESUMO
A violência de gênero tem sido fortemente associada a prejuízos na saúde mental das mulheres, tais como a configuração de quadros de depressão, ansiedade, fobias, transtorno pós-traumático, suicídio, problemas alimentares, etc. O presente artigo teve como escopo analisar se, e como, as políticas públicas desenvolvidas para as mulheres e aquelas resultantes da Reforma Psiquiátrica dialogam entre si no que tange ao tema dos impactos da violência na saúde mental das mulheres. Para isto, foi realizada uma análise dos três Planos Nacionais de Políticas para as Mulheres (20042013), da Lei Maria da Penha (2006) e da Política Nacional de Enfrentamento à Violência contra as Mulheres (2011), das quatro Conferências Nacionais de Saúde Mental (1987-2004) e da Lei da Reforma Psiquiátrica (2001) buscando-se evidenciar as interseccionalidades (in)existentes entre ambas as políticas. A análise demonstrou que o diálogo entre estes documentos ainda é incipiente e a violência de gênero contra as mulheres não tem sido tratada claramente como um fator de risco para a saúde mental. Faz-se mister visibilizar esta relação e propor aos serviços de saúde intervenções mais eficazes para lidar com mulheres que foram ou estão sendo vítimas de violência.
\end{abstract}

Palavras chaves: violência, saúde, gênero, políticas públicas.

\section{ABSTRACT}

The gender violence has been widely associated with disorders in women's mental health, such as depression, anxiety, phobias, post traumatic disorders, suicide, eating disorders, etc. The purpose of this article was to analyze whether and how the public policies developed for women and those resulting from the Psychiatric Reform dialogue with each other regarding the impacts of violence in women's mental health. To accomplish this goal, an analysis of the three National Plans of Politics for Women (2004-2013), the Maria da Penha Law (2006), the National Politic of Combating Violence Against Women (2011), the four National Conferences of Mental Health 
(1987-2004) and the Law of the Psychiatric Reform (2001) was done, trying to point out the existence (or not) of the intersectionality between them. The analysis showed that the conversation between this documents still is incipient and that gender violence against women has not being treated as a risk factor to mental health. Therefore, it is important to give visibility to this relation an to come up with more effective interventions for the health care system deal with women who are or have been victims of violence.

Keywords: violence, health, gender, public policies.

\section{RESUMEN}

La violencia de género ha sido fuertemente asociada con alteraciones en la salud mental de las mujeres, tales como el establecimiento de diagnósticos de depresión, ansiedad, fobias, trastorno postraumático, el suicidio, desórdenes alimentarios, etc. Este articulo tiene como alcance analizar si, y cómo, las políticas públicas desarrolladas para mujeres y las que resultan de la Reforma Psiquiátrica dialogan entre sí en lo que se refiere a los impactos de la violencia en la salud mental de las mujeres. Para esto, se realizó un análisis de los tres Planes Nacionales de Políticas para las Mujeres (20042013), de la Ley Maria da Penha (2006), de la Política Nacional de Enfrentamiento de la Violencia contra las Mujeres (2011), de las cuatro Conferencias Nacionales de Salud Mental (1987 hasta 2004) y de la Ley de la Reforma Psiquiátrica, tratando de resaltar interseccionalidades existentes (o no) entre ambas políticas. El análisis mostró que el diálogo entre estos documentos es todavía incipiente y la violencia de género contra las mujeres no ha sido claramente tratada como un factor de riesgo para la salud mental. Es importante dar visibilidad a esta relación y proponer a los servicios de salud intervenciones más eficaces para hacer frente a las mujeres que han sido o están siendo víctimas de la violencia.

Palabras claves: violencia, salud, género, políticas públicas.

\section{I ntrodução}

O movimento feminista se consolidou no Brasil, juntamente com os estudos de gênero, a partir do final dos anos 70. Este processo ocorreu concomitantemente com a redemocratização política e o fortalecimento de diversos movimentos sociais. Na década de 1980, a questão política dominou os feminismos, surgindo grupos temáticos, entre eles os que tratavam de questões da saúde e da violência contra as mulheres, assim como grupos de apoio às mulheres vítimas de violência (Narvaz, 2009). Na década de 90, a violência contra as mulheres foi declarada, segundo a Organização Mundial da Saúde (OMS), como um problema de saúde pública e que diz respeito aos diversos setores: social, jurídico, político e de saúde (OMS, 2005). Diante desta mobilização social e política, o Brasil passou a ser signatário de diversos acordos, tratados e convenções nacionais e internacionais, assumindo o compromisso de erradicar a discriminação, os estereótipos de gênero e a violência contra as mulheres. Dentre os documentos assinados encontram-se a Convenção para a Eliminação de todas as Formas de Discriminação 
contra a Mulher (CEDAW), a Convenção Interamericana para Prevenir, Punir e Erradicar a Violência contra a Mulher, conhecida como Conferência de Belém do Pará e a IV Conferência Mundial sobre a Mulher (Narvaz, 2009).

Para manter o compromisso assinado nestas conferências, impulsionar e articular a institucionalização da questão de gênero e implantar políticas públicas foi criada, em 2003, a Secretaria Especial de Políticas para as Mulheres (SPM). Antes de sua criação, as iniciativas de enfrentamento à violência contra as mulheres eram, de maneira geral, ações isoladas e relacionadas a duas estratégias: a capacitação de profissionais da rede de atendimento às mulheres em situação de violência e a criação de serviços especializados de atendimento às mulheres. A partir de 2003 , as políticas públicas para o enfrentamento da violência passaram a ser ampliadas e a incluir ações integradas, como: "criação de normas e padrões de atendimento, aperfeiçoamento da legislação, incentivo à constituição de redes de serviços, apoio a projetos educativos e culturais de prevenção à violência e ampliação do acesso das mulheres à justiça e aos serviços de segurança pública" (SPM, 2011, p.7). À SPM foi designado o status de Ministério (que vigorou até o fim de 2015) e ela passou a desenvolver ações com outros Ministérios e Secretarias, dentre eles o Ministério da Saúde, a fim de incorporar as especificidades de gênero nas políticas públicas e o estabelecimento das condições necessárias para alcançar a plena cidadania das mulheres (Narvaz, 2009).

Apesar dos avanços e da articulação da SPM, o Brasil ainda é um país extremamente machista (I pea, 2014) e possui uma alta incidência de casos de violência contra as mulheres (Instituto Avon, 2014). De acordo com o Mapa da Violência (Waiselfisz, 2015), pesquisa realizada pela FLACSO/BR, o Brasil ocupa o 5o lugar nas taxas de homicídio feminino em uma amostra de 83 países. Em comparação com o Reino Unido, por exemplo, o Brasil tem 48 vezes mais homicídios femininos, dado que exemplifica a magnitude da violência e da morte de mulheres no país.

A violência contra as mulheres gera impactos socioeconômicos, assim como impactos na saúde (OMS, 2005, 2010, 2013). Segundo Henrica, Jansen, Heise, Watts \& Garcia-Moreno (2008), mulheres violentadas demonstram ter uma piora na saúde e passam mais dias acamadas do que mulheres que não sofreram violência. Neste sentido, Schraiber e D'Oliveira (1999) afirmam que mulheres vítimas de violência parecem utilizar mais os serviços de saúde do que a população em geral. Além disto, a violência física, sexual e psicológica tem sido associada com diversos problemas psiquiátricos tais como depressão, ansiedade, fobias, estresse pós-traumático, suicídio, tentativa de suicídio, abuso de álcool e drogas, insônia, exacerbação de sintomas psicóticos, problemas alimentares, 
depressão pós-parto, transtorno bipolar (Henrica, et al., 2008; Rose, Trevillion, Woodall, Morgan, Geder, Howard, 2011; Trevillion, Hughes, Feder, Borschmann, Oram, \& Howard 2014).

Estes dados mostram que a opressão e a violência de gênero levam ao sofrimento e a uma diversidade de problemas psicológicos (Chesler, 2005). Portanto, ao se refletir sobre as políticas públicas, deve-se se levar em consideração os desdobramentos gerados pela violência, a fim de que intervenções mais eficazes sejam planejadas.

\section{Saúde Mental e Reforma Psiquiátrica Brasileira}

Paralelamente aos avanços dos direitos das mulheres, também mobilizados pelo contexto da redemocratização brasileira, surgia, em 1978, o Movimento dos Trabalhadores em Saúde Mental (MTSM), que se tornou ator estratégico pelas reformas no campo da saúde mental. A psiquiatria brasileira vivia um momento, em conformidade com a psiquiatria mundial, de medicalização da loucura, que tornava a doença mental objeto exclusivo de um saber e de uma prática especializada, a biomédica (Engel, 2004).

Assim, a ideia inicial do Movimento era prover uma crítica ao modelo psiquiátrico clássico, mostrando sua presença na prática das instituições psiquiátricas. Buscou-se também entender a função social da psiquiatria para além de seu papel médico-terapêutico. A partir da década de 1980, o movimento passou a ser chamado de Movimento pela Reforma Psiquiátrica Brasileira, e teve como ponto de virada dois eventos importantes: a I Conferência Nacional de Saúde Mental e o II Encontro Nacional dos Trabalhadores em Saúde Mental. A conferência representou o fim da trajetória sanitarista, com o olhar voltado apenas para o sistema de saúde, e deu início à desconstrução do cotidiano dos manicômios, chamada de desinstitucionalização.

No encontro que ocorreu no mesmo ano em Bauru - SP, o movimento perdeu a natureza técnico-cientifica e se tornou social em busca de transformações no campo da saúde mental com o lema "Por uma Sociedade sem Manicômios". Assim, passou a requerer 0 envolvimento da sociedade na discussão e nos direcionamentos a serem tomados em relação à doença mental e à assistência psiquiátrica (Amarante, 1995).

Em 2001, a Lei 10.216/2001 (Brasil, 2001), conhecida como "Lei da Reforma Psiquiátrica", foi aprovada (com vários cortes em seu texto) após vários anos de tramitação no Congresso Nacional e depois de diversas mobilizações da sociedade civil organizada. A Lei "dispõe sobre a proteção e os direitos das pessoas portadoras de transtornos mentais e redireciona o modelo assistencial em saúde mental".

A reforma trouxe importantes avanços para a área de saúde mental no Brasil (Tenório, 2002). No entanto, há pontos que precisam ser 
melhor desenvolvidos, dentre eles, podemos apontar a importação de um modelo psiquiátrico biologizante e a invisibilidade do gênero.

Andrade (2010) e Maluf (2010) problematizam essa importação do modelo psiquiátrico biologizante, ainda que este seja criticado pela reforma. Segundo a primeira autora, a reforma psiquiátrica juntamente com a disseminação de uma cultura psicanalítica promoveu um alargamento do que é considerado patológico. Assim, a reforma teve dificuldade em consolidar um de seus pressupostos: ao invés de se abrir para a pluralidade de experiências, seu foco ainda se volta para (ou se baseia em) a realização de diagnósticos, categorização e medicamentalização da vida. A segunda autora corrobora com esta ideia ao afirmar que dentro dos movimentos sociais há uma confusão entre os conceitos de universalização e democratização (que são baseados nos princípios do Sistema Único de Saúde - SUS) com a distribuição de medicamentos. Assim, as concepções de adoecimento, cura e saúde criadas pela indústria farmacêutica são pouco questionadas e a saúde mental acaba por ser tratada de maneira reificada.

Um exemplo desta reificação da saúde mental é a falta de olhar para um viés de gênero na criação de diagnósticos e no tratamento/atendimento nos serviços de saúde mental. Zanello (2014a) afirma que o viés de gênero provoca um grande desconforto para a área de saúde mental, "pois abala as certezas de uma suposta neutralidade, traz o íntimo para o político e questiona as próprias relações de poder neste campo, bem como seus valores" (p. 116). Com esta ideia, a autora sublinha que todo diagnóstico implica um ato hermenêutico, calcado em valores dos próprios profissionais de saúde, dentre os quais destacam-se os estereótipos de gênero. Neste sentido, aponta-se que o nível de "tolerância" para que um comportamento seja visto como sintomático é diferente para homens e mulheres, como é o caso da agressividade e da expressão da sexualidade (Zanello, 2014a). Outro exemplo trata da tendência em ver o sofrimento expressado pelas mulheres como dramático ou histriônico (Zanello \& Silva, 2012). Muitas situações de violência acabam por ser desqualificadas neste tipo leitura, aparentemente científica, mas profundamente preconceituosa (Zanello, 2014b).

A invisibilidade do gênero na reforma psiquiátrica impossibilita a criação de políticas públicas levando em consideração as especificidades de ser homem ou mulher em nossa cultura, bem como reifica e biologiza o sofrimento mental, separando-o de questões sociais. Dentre os desdobramentos da invisibilidade de gênero da reforma, destaca-se a invisibilidade da violência contra as mulheres.

Segundo estudo realizado por Barbosa, Dimenstein e Leite (2014), mulheres que viviam situações de violência e possuíam transtornos mentais em uma comunidade do Rio Grande do Norte não 
conseguiram encontrar nos serviços um local que as atendesse de maneira integral. Nesta pesquisa foram realizadas entrevistas com profissionais que atuam tanto nos Centros de Referência de violência contra as mulheres, como em Centros de Atenção Psicossocial. Foi possível perceber com o estudo que os profissionais acolhiam apenas a demanda para a qual o serviço era direcionado prioritariamente. Desta forma, serviços de saúde mental acolhiam, apenas, a demanda do sofrimento mental e serviços de atendimento à violência focavam seu atendimento na violência sofrida e não se preocupavam com a saúde mental. Assim, as mulheres ficavam desassistidas em pelo menos uma de suas demandas e não se qualificavam, devidamente, os impactos da violência sobre a saúde mental delas. Barbosa, Dimenstein e Leite (2014) destacam que, apesar das políticas serem especializadas em diferentes setores de atendimento, é necessário que haja uma maior articulação para que se obtenha uma melhor resolutividade.

O presente artigo tem como objetivo pesquisar e discutir que tipo de interface existe (ou não) entre as políticas públicas para as mulheres e as políticas de saúde mental no Brasil. Para isto, busca-se analisar como os Planos Nacionais de Políticas para as Mulheres (SPM, 2004 2008, 2013), a Lei Maria da Penha (BRASIL, 2006) e a Política Nacional de Enfrentamento à Violência contra as Mulheres (SPM, 2011) delinearam o atendimento à saúde mental das mulheres em situação de violência e como as Conferências em Saúde Mental (MS, 1987, 1992, 2001, 2004) e a Lei da Reforma Psiquiátrica (BRASIL, 2001) precisam (ou não) a especificidade deste público.

\section{Políticas Para as Mulheres: Como é Tratado o Tema do I mpacto da Violência Sobre a Saúde Mental}

Os PNPMs tiveram, como objetivo geral, a efetividade das políticas públicas para as mulheres. No total, foram realizadas três conferências, que geraram três planos. O I Plano Nacional de Políticas para as Mulheres (I PNPM), criado em 2004, foi resultado da I Conferência Nacional de Políticas para as Mulheres e teve como objetivo a efetivação dos direitos das mulheres. As ações previstas neste documento envolveram quatro eixos de atuação: autonomia, igualdade no mundo do trabalho e cidadania; educação inclusiva e não sexista; saúde das mulheres, direitos sexuais e direitos reprodutivos; e, enfrentamento à violência contra as mulheres (Narvaz, 2009; SPM, 2004).

Neste I PNPM, o foco de atuação manteve-se na saúde reprodutiva e na redução da mortalidade materna, o que provocou uma lacuna em outras áreas que compreendem a saúde integral das mulheres, como a saúde mental. Apesar disso, este plano incluiu o tema no capítulo 
referente à "saúde das mulheres, direitos sexuais e direitos reprodutivos", relacionando, ainda que incidentalmente, a saúde mental ao ciclo biológico e reprodutivo das mulheres. O plano visou atingir a saúde mental ao estabelecer como meta a implantação de "projetos pilotos de um modelo de atenção à saúde mental das mulheres na perspectiva de gênero, em 10 municípios com Centros de Atenção Psicossocial (CAPS)" (SPM, 2004, p. 66). Entretanto, estes projetos não foram implementados.

O II Plano Nacional de Políticas para as Mulheres (II PNPM) ampliou os eixos de atuação para onze, são eles: autonomia econômica e igualdade no mundo do trabalho, com inclusão social; educação inclusiva, não-sexista, não-racista, não-homofóbica, não-lesbofóbica; saúde das mulheres, direitos sexuais e direitos reprodutivos; enfretamento de todas as formas de violência contra as mulheres; participação das mulheres nos espaços de poder e decisão; desenvolvimento sustentável no meio rural, na cidade e na floresta, com garantia de justiça ambiental, soberania e segurança alimentar; direito à terra, moradia digna e infra-estrutura social nos meios rural e urbano, considerando as comunidades tradicionais; cultura, comunicação e mídias igualitárias, democráticas e não discriminatórias; enfrentamento do racismo, sexismo e lesbofobia; enfrentamento das desigualdades geracionais que atingem as mulheres, com especial atenção às jovens e idosas; e, gestão e monitoramento do plano (SPM, 2008).

Este II PNPM manteve o tema da saúde mental no capítulo "saúde das mulheres, direitos sexuais e direitos reprodutivos". Neste plano, permanece a relação entre a saúde mental e ciclo reprodutivo, sendo este inclusive o foco das ações, pois há a afirmação de que

os transtornos mentais e de comportamento associados ao puerpério merecem ser mais investigados. Pesquisa realizada em 24 capitais e no DF, em 2001, num universo de 3265 mulheres, identificou 97 mortes por suicídio, associadas à depressão, inclusive relacionada ao pós-parto (SPM, 2008, p. 76).

Em relação à depressão pós-parto, Zanello (2016) critica a forma como ela é analisada e propõe que seja feita uma leitura de gênero da questão. Para a autora, nos últimos dois séculos, houve a construção de um ideal de maternidade e uma associação naturalizante entre a capacidade de procriar (das mulheres) com a capacidade de cuidar (humana). O resultado foi um excesso de tarefas e responsabilidades "maternas" construídas sobre as mulheres, impactando a saúde mental das mesmas quando na situação de serem mães. A crítica em relação à depressão pós parto também tem relação com a crítica da leitura biologizante, prevalente 
em nossa cultura (depressão pós parto como sinônimo de desequilíbrio hormonal), a qual não apenas escamoteia estas questões, como as invalida, pelo seu caráter reducionista e silenciador do sofrimento das mulheres.

O II PNPM propôs que as ações de saúde busquem a integralização e estabeleceu como meta a implantação de "cinco experiências-piloto, uma por região, de um modelo de atenção à saúde mental das mulheres na perspectiva de gênero" (SPM, 2008, p. 80), que foi realizada de forma tímida. Além disto, também priorizou "promover a implantação de um modelo de atenção à saúde mental das mulheres na perspectiva de gênero, considerando as especificidades étnicoraciais" (SPM, 2008, p. 81).

No tópico de "enfrentamento a todas as formas de violência contra as mulheres", o plano traz a seguinte reflexão: "os homens tendem a ser vítimas de uma violência predominantemente praticada no espaço público, as mulheres sofrem cotidianamente com um fenômeno que se manifesta dentro de seus próprios lares" (SPM, 2008, p. 95). Embora esta afirmação seja corroborada pelo o dado de que a maior parte da violência explícita sofrida pelas mulheres acontece no ambiente doméstico (Instituto Avon, 2014), ela invisibiliza as violências que acontecem, no espaço público, no cotidiano das mulheres. Estas violências, por nem sempre serem físicas, são naturalizadas e menosprezadas pela sociedade. Por exemplo, 0 assédio que as mulheres sofrem ao andar nas ruas da cidade, independente do horário, o qual suscitou a criação de campanhas para tentar coibir estas condutas dos homens; as propagandas que objetificam os corpos das mulheres criando um ideal de beleza inatingível, entre outros.

O III Plano Nacional de Políticas para as Mulheres (III PNPM), realizado em 2013, teve como enfoque a transversalidade como forma de transformação dos espaços cristalizados de opressão e invisibilidade das mulheres dentro do aparato estatal. A transversalidade é entendida como construto teórico, que visa ressignificar conceitos chave que possibilitam o entendimento mais amplo na produção de desigualdades, e como conjunto de ações e de práticas políticas e governamentais, que constituem uma nova estratégia para o desenvolvimento democrático como processo estruturado em função da inclusão das diferenças no âmbito público e privado (SPM, 2013).

Este III PNPM estabeleceu como linha de ação a promoção da atenção à saúde mental das mulheres, e considerou várias especificidades, tais como as raciais, étnicas, de origem, de classe social, de idade, de orientação sexual, de identidade de gênero. $E$ ainda, as especificidades de deficiência, as mulheres em situação de prisão ou em situação de violência, incluindo mulheres do campo, da floresta, de quilombos e de comunidades tradicionais (SPM, 2013). 
Dentro desta linha de ação, uma que merece destaque é a "3.10.4" pelo fato de propor um olhar para a especificidade do adoecimento mental das mulheres vítimas de violência: "implantar ações específicas para atenção às mulheres em situação de violência nos serviços de saúde e nos serviços de saúde mental" (SPM, 2013, p. 39). O que podemos perceber, portanto, é que neste documento há uma maior sensibilidade em relação ao adoecimento mental de mulheres, decorrente das violências.

Além dos PNPMs, faz-se mister analisar a Lei Maria da Penha e a Política Nacional de Enfrentamento à Violência contra as Mulheres. Estes documentos são marcos brasileiros importantes no enfrentamento da violência contra as mulheres, sendo a Lei Maria da Penha considerada pela OMS, em 2012, uma das três melhores leis do mundo de combate à violência contra as mulheres. A Política Nacional surgiu a partir de propostas do I PNPM e oferece diretrizes sobre como devem ser realizadas as políticas públicas para as mulheres no Brasil. Assim, analisar como é tratada a saúde mental nestes documentos é fundamental, pois ambos são importantes norteadores de políticas no cenário nacional.

A Lei Maria da Penha (BRASIL, 2006), promulgada em 2006, é a normativa de prevenção, assistência e punição à violência doméstica contra as mulheres mais relevante do Brasil. Foi criada a partir da luta de mulheres que insistiram em uma política mais incisiva de punição aos agressores e proteção às vítimas de violência, e estabeleceu mecanismos para coibir a violência doméstica e familiar contra a mulher. Além disto, não é uma lei meramente punitiva, mas propôs que fossem garantidas medidas de proteção e prevenção à integridade física das mulheres. Também buscou o empoderamento das mulheres para romper com a reprodução da violência de gênero na sociedade (Pasinato, 2011).

A saúde mental é tratada, por esta lei, de forma muito abrangente. Ela propõe a "preservação da integridade física e psicológica" da mulher em situação de violência. Porém não estabelece como deve ser realizada a preservação da integridade psicológica. Já no que concerne a integridade física, o texto da lei propõe uma atenção conjunta com os serviços de saúde para atender as lesões corporais e a demanda "fisiológica" da violência sexual. Isto fica evidente no artigo 9o, § 3으, que postulou:

A assistência à mulher em situação de violência doméstica e familiar compreenderá o acesso aos benefícios decorrentes do desenvolvimento científico e tecnológico, incluindo os serviços de contracepção de emergência, a profilaxia das Doenças Sexualmente Transmissíveis (DST) e da Síndrome da Imunodeficiência Adquirida (AIDS) e outros procedimentos 
médicos necessários e cabíveis nos casos de violência sexual (BRASIL, 2006).

A Política Nacional de Enfrentamento à Violência contra as Mulheres, de 2011, teve por finalidade estabelecer conceitos, princípios, diretrizes e ações de prevenção e combate à violência contra as mulheres, assim como de assistência e garantia de direitos às mulheres em situação de violência, conforme normas e instrumentos internacionais de direitos humanos e legislação nacional. Além disso, foi estruturada a partir do IPNPM, o qual estabeleceu, no eixo IV de enfrentamento à violência contra as mulheres, a criação de uma Política Nacional (SPM, 2011). Apesar de a ênfase deste documento ser a prevenção e o combate à violência, também trata da assistência. Ainda que a violência tenha um grande impacto sobre a saúde mental das mulheres, este tema sequer é mencionado. $O$ documento, ao tratar do tema, apenas especifica as formas de violência contra as mulheres ou cita trechos da lei, ou seja, não faz considerações relevantes a respeito do assunto.

A partir da análise dos PNPMs, da Lei Maria da Penha e da Política Nacional de Enfrentamento à Violência contra as Mulheres destaca-se a inclusão da saúde mental dentro do capítulo intitulado "Saúde das mulheres, direitos sexuais e direitos reprodutivos". Maluf (2010) afirma que nos discursos de quem elabora as políticas públicas, a perspectiva de gênero é reduzida ao que seria especificidades femininas quanto à aflição e ao sofrimento, e que estão ligadas, em geral, a noção do "ciclo de vida" biológico, ou seja, prevalece um modelo fisicalista e de racionalização médica de diferença de gênero. Assim, a eleição deste capítulo para abordar a saúde mental, reforçou, ainda que talvez não intencionalmente, a ideia do adoecimento mental das mulheres ligado às questões biológicas e pouco às questões sociais.

Outro dado comum a todos os PNPMs é a existência de um capítulo específico de "enfrentamento de todas as formas de violência contra as mulheres". Entretanto, ao analisar este capítulo pôde-se observar que há uma invisibilidade em relação ao adoecimento psíquico como decorrente da violência sofrida. O que se observa é que a relação entre violência e saúde mental é incipiente, pois ainda se pensa a violência com ações de âmbito político-social (tais como grupos de enfrentamento e prioridade ao receber benefício financeiro do governo) e a saúde mental continua inserida, acriticamente, no âmbito biológico da saúde sexual e reprodutiva. 


\section{Princípios da Saúde Mental no Brasil e Violência contra as Mulheres: é Reconhecida a Especificidade do Adoecimento Psíquico de Mulheres em Função Da Violência de Gênero?}

As Conferências de Saúde Mental tiveram um papel estratégico na elaboração e consolidação dos princípios da Reforma Psiquiátrica. A I Conferência, realizada em 1987, teve seu foco no impasse do modelo centrado no hospital e predominantemente baseado no modelo médico-psiquiátrico, considerado ineficaz e oneroso para os usuários e a sociedade, violando os direitos humanos fundamentais. A conferência foi estruturada conforme três temas básicos: I Economia, Sociedade e Estado: impactos sobre saúde e doença mental; II - Reforma sanitária e reorganização da assistência à saúde mental; III - Cidadania e doença mental: direitos, deveres e legislação do doente mental (MS, 1987, 2001).

O foco desta conferência foi humanizar e promover uma melhor atenção aos "portadores de transtornos mentais". Entretanto, acabou por tratar estas pessoas, ainda que incidentalmente, de maneira reificada e universal, ou seja, neste relatório não é possível observar a interface com as especificidades de raça, gênero, classe e orientação sexual. O uso do termo "gênero", por exemplo, foi relacionado à espécie, tipo, qualidade ou modo de ser e fazer, como na expressão: “loucos de todo gênero" (p. 23). Assim, não se fez uma leitura de gênero como categoria de análise histórica dos papeis sociais definidos para homens e mulheres.

A II Conferência Nacional de Saúde Mental, realizada em 1992, aprofundou as críticas ao modelo hegemônico e também formalizou o esboço de um novo modelo assistencial, significativamente diverso, não só na lógica, conceitos, valores e estrutura da rede de atenção, mas também na forma concreta de lidar com as pessoas com a experiência de transtornos mentais, a partir de seus direitos de cidadania (MS, 2001). Esta também foi dividida em três temas centrais que centralizaram as deliberações dos delegados, a saber: rede de atenção em saúde mental; transformação e cumprimento de leis; e, direito à atenção e direito à cidadania.

Esta conferência pouco evoluiu no sentido de se analisar as especificidades do "doente" e do adoecimento mental. Assim, as questões de ordem social permaneceram invisibilizadas.

A III Conferência de Saúde Mental foi realizada em 2001, após a aprovação da Lei da Reforma Psiquiátrica (BRASIL, 2001). Teve o tema "Cuidar, sim. Excluir, não" como foco das discussões, em consonância com a Organização Mundial da Saúde, que propôs a centralidade deste tema para o ano de 2001. Também foi discutido o tema: "Efetivando a Reforma Psiquiátrica, com Acesso, Qualidade, Humanização e Controle Social", que era/é atual e fundamental para a realidade brasileira. Assim, os seguintes subtemas tiveram papel 
central nos debates realizados pela Conferência: financiamento; recursos humanos; controle social, e acessibilidade, direitos e cidadania. Segundo a avaliação da conferência, descrita em seu relatório final, ela representa o

fortalecimento do consenso sobre a proposta da Reforma Psiquiátrica, com toda a sua pluralidade e diversidade interna, elaborando propostas e estratégias para efetivar e consolidar um modelo de atenção em saúde mental totalmente substitutivo ao manicomial. Todo este percurso vem reafirmar que o processo histórico da Reforma Psiquiátrica, compreendido como transformação de saberes, práticas, valores sociais e culturais, é marcado por tensões, desafios e conflitos (MS, 2001, p. 19).

Esta conferência, de modo geral, buscou pensar nas interseccionalidades do adoecimento mental. Entre elas, encontra-se uma maior preocupação em relação a situações de violência. Por exemplo, no capítulo sobre a política de saúde mental e a organização de serviços, são propostos: "garantir a definição de uma política intersetorial para atendimento às pessoas portadoras de deficiência mental articulando as ações da saúde, educacional, assistência social, poder judiciário e atenção às vítimas de violência" (MS, 2001, p. 28) e "implementar ações preventivas de saúde mental, que articulem práticas de promoção de cuidados às vítimas de violência e de desinstitucionalização" (MS, 2001, p. 38).

Nestes casos, não é possível identificar quem são as "vítimas de violência", ou seja, elas são tratadas de maneira universal. As formas e o sentido da violência são diferentes a depender das especificidades do grupo na qual ela ocorre, portanto, as ações governamentais para erradicar este problema também devem ser distintas. Assim, não especificar a "vítima de violência" pode impedir a criação de políticas públicas mais adequadas e eficazes às demandas dos diversos grupos sociais.

Ao tratar do acesso aos serviços de saúde mental, o relatório propõe que "deve ser garantida uma atuação intersetorial da política de saúde mental voltada àqueles segmentos de usuários em situação de maior risco: mulheres vítimas de violência doméstica, crianças, adolescentes e idosos" (MS, 2001, p. 115). Há, neste fragmento, uma preocupação com as mulheres vítimas de violência. Entretanto, elas aparecem ao lado, indiscriminadamente, de crianças, adolescentes e idosos. As mulheres são um pouco mais da metade da população brasileira $(52,2 \%)$, já as classificações "criança", "adolescente" e "idoso" dizem acerca de etapas da vida, ou seja, apontam vulnerabilidades diferentes que podem se assomar ao gênero. Neste sentido, pouco se fala exclusivamente das mulheres, apesar de um 
estudo do Instituto Avon (2014), retratar que três em cada cinco mulheres no Brasil admitiram ter sido vítimas de violência física ou sexual. Ou seja, trata-se de uma epidemia, de um problema de saúde pública, da qual os serviços de saúde mental não podem e nem devem se esquivar. Além disto, não cabe apenas aos serviços de saúde se responsabilizarem pelo problema, mas deve haver uma (co)responsabilidade em relação ao atendimento a estas mulheres, sobretudo quando há desdobramentos evidentes em sua saúde mental, a ponto de receberem um diagnóstico psiquiátrico (Campos \& Zanello, 2016).

No capítulo sobre Direitos e Cidadania, o texto tangencia a notificação (que neste momento histórico ainda não era compulsória) dos casos de violência: "garantir que os médicos registrem, nos prontuários clínicos e laudos periciais realizados em portadores de transtornos mentais, as lesões observadas, em conformidade com o código de ética, como já se procede em casos de violência de gênero e contra crianças e adolescentes" (MS, 2001, p. 133).

A IV Conferência de Saúde Mental, empreendida em 2004, reafirmou os princípios gerais da reforma psiquiátrica em curso no país. A Conferência se manifestou contrária a todas as propostas de privatização e terceirização de serviços, na garantia de um sistema público e estatal da saúde mental. Também reafirmou a necessidade da participação ativa dos usuários, na produção do cuidado e no ativismo junto aos serviços. Ela ocorreu depois da criação da Secretaria de Políticas para as Mulheres e, coincidentemente ou não, nesta conferência, existe uma maior sensibilização para a questão da violência.

No capítulo de Direitos Humanos e Cidadania, há propostas que visaram, sob um enfoque de gênero - aqui visto como categoria de análise sócio histórica -, um cuidado com a atenção à saúde mental das mulheres, com a finalidade de: melhorar a informação sobre as mulheres com sofrimento psíquico no SUS; qualificar a atenção dada à elas; incluir um enfoque de gênero e raça na atenção às mulheres; promover a integração com a sociedade civil, a fim de aumentar a participação nas políticas de atenção às mulheres com sofrimento mental; e defender a descriminalização do aborto. $O$ foco em questões das mulheres é fundamental, mas não necessariamente fez com que os serviços voltassem a atenção para as especificidades de ser mulher e na interlocução do sexismo com a saúde mental.

Há nesta conferência um capítulo relacionado à violência e à saúde mental. Entretanto, neste tópico a palavra "mulher" não foi citada nenhuma vez. Isso pode indicar a invisibilidade da violência contra as mulheres na interface com as políticas de saúde mental. Este fato é preocupante, tendo em vista a forte correlação entre a violência e o adoecimento mental (Henrica et al., 2008; Rose et al. 2011; Trevillion et al., 2014), e a elevada presença destas mulheres nos 
serviços de saúde e de saúde mental em específico (Schraiber, 1999; Barbosa, Dimenstein \& Leite, 2014; Campos \& Zanello, 2016). A notificação dos casos de violência se tornou compulsória desde 2003, ainda assim o documento não ressalta esta obrigatoriedade, o que vai ao encontro dos resultados de pesquisas recentes que apontam que a notificação da violência contra a mulher não vem sendo realizada como deveria ser no sistema de saúde mental (Galvão \& Dimenstein, 2009; Mattos, Ribeiro \& Camargo, 2012; Pedrosa \& Zanello, 2017b).

A Lei da Reforma Psiquiátrica, sancionada em 2001, dispôs sobre a proteção e os direitos das pessoas portadoras de transtornos mentais e redirecionou o modelo assistencial em saúde mental. Na lei, ainda que não intencionalmente, houve a reificação do adoecimento mental, no sentido de não se questionar a própria natureza do adoecimento e suas interfaces com questões sociais. Quando a lei tratou da violência, houve uma preocupação com a violência contra as pessoas com transtorno mental, enfatizando uma anterioridade (temporal) do transtorno à violência, mas pouco abordou os transtornos decorrentes das violências ou a participação das violências na configuração dos transtornos. Por exemplo, no inciso III do parágrafo único do artigo 20: "são direitos da pessoa portadora de transtorno mental: III- ser protegida contra qualquer forma de abuso e exploração" (BRASIL, 2001).

Foi possível assim observar através da análise dos documentos (as quatro Conferências Nacionais de Saúde Mental e a Lei da Reforma Psiquiátrica), que pouco se trata das especificidades das pessoas "portadoras de transtorno mental". De maneira geral, elas são tratadas de forma universal, invisibilizando questões de sexo, raça e classe. Entretanto, existem grupos, considerados minorias, que conseguiram, ao longo das conferências, ainda que de forma incipiente, manter o foco neles mesmos, como é o caso da população LGBT (Lésbicas, Gays, Bissexuais, Travestis e Transexuais), que possuem propostas exclusivas para si. Cabe frisar, no entanto, que, embora as mulheres representem $52,2 \%$ da população brasileira (SPM, 2013), as leis e conferências pouco focam exclusivamente nelas e no sofrimento a que elas são submetidas pelo simples fato de serem mulheres: como o sexismo e violência de gênero.

Ao tratarem da questão da violência, os documentos não analisam dois aspectos importantes. O primeiro deles é em relação ao sujeito receptor da violência, ou seja, quem é a vítima, assim a tratam como sendo de uma única espécie, e não se pensa nas diferenças de cuidados necessários a um idoso, uma criança ou uma mulher vítima de violência. O segundo aspecto é relacionado, como já mencionamos, a estes documentos não pensarem na violência como fator partícipe da configuração do quadro de adoecimento mental, e sim, ela sendo sofrida pela pessoa que já apresenta o transtorno mental. Este segundo aspecto acaba por facilitar uma invisibilidade 
da violência no atendimento de transtornos mentais, os quais parecem ser vistos, muitas vezes, como entidades independentes, separadas do próprio histórico da violência, como sugerem os estudos de Dimenstein (2013) e Zanello (2014b).

\section{Conclusões}

A análise dos documentos relacionados às políticas para as mulheres e os relacionados à saúde mental no Brasil demonstraram que o diálogo entre eles ainda é incipiente. Este dado corrobora com aquilo que é visto na prática dos cotidianos de saúde, como demonstrado por Barbosa, Dimenstein e Leite (2014) e Pedrosa \& Zanello (2017b). Assim, falta a integralidade nas ações acerca do adoecimento mental em mulheres com histórico de violência.

Nos documentos da SPM, como vimos, o tópico da saúde mental das mulheres foi inserido juntamente à saúde sexual e reprodutiva, ou seja, relacionado ao ciclo reprodutivo. Desta forma, o adoecimento mental corre o risco de ser reificado e tratado pelo viés biomédico, com o foco na menarca, climatério, puerpério. A ligação da saúde mental com a biológica acaba por promover a biologização e a medicalização do sofrimento e, mais uma vez, afasta as questões sociais que afligem as mulheres do contexto da saúde. Paralelamente a isto, ao falar da violência contra a mulher, o aspecto psicológico é visto como algo a ser preservado, como por exemplo, na Lei 11340/2006 (Maria da Penha), o texto traz, diversas vezes, a expressão "preservação da integridade física e psicológica". Porém, os documentos não fazem uma reflexão sobre como a mulher, que teve sua integridade física e psicológica violada, deve ser tratada e nem sobre o impacto desta violação para sua saúde física e, principalmente, mental. Assim, o sofrimento mental causado pela violência fica, de certa forma, invisibilizado nestes documentos.

Já nos documentos de saúde mental, percebe-se uma tentativa de olhar para as mulheres, mas o foco ainda se dá no "portador" de transtorno mental que sofre a violência e não o transtorno como sendo configurado, em grande parte, pelas próprias situações de violência. Este fato invisibiliza especificidades das histórias de vida que levaram ao sofrimento e ao adoecimento. Assim, em conformidade com os pressupostos da psiquiatria biomédica, descontextualiza os sintomas e reifica a "doença mental".

Embora a literatura mostre que a violência é um fator de risco para a saúde mental, é importante que este dado chegue a quem elabora as leis ou participa de conferências que norteiam as mesmas. Pode-se depreender da leitura destes documentos que a violência de gênero contra as mulheres não é tratada claramente como um fator de risco para a saúde mental. Faz-se mister visibilizar esta relação e propor 
aos serviços de saúde, principalmente aos serviços de saúde mental, intervenções mais eficazes para lidar com mulheres que foram ou estão sendo vítimas de violência, para que elas não sejam apenas medicalizadas e silenciadas, configurando uma nova situação de violência, institucional.

Um exemplo de intervenção possível seria a construção de grupos de mulheres, em uma escuta clínica sob a perspectiva de gênero, a qual pode se constituir como um dispositivo em saúde mental, complementar a outras ações terapêuticas (Pedrosa \& Zanello, 2017a). Além disso, sugere-se que o tópico da saúde mental seja problematizado, nas próximas PNPMs, em um eixo próprio, separada das questões que abordam a saúde sexual e reprodutiva das mulheres.

\section{Referências}

Amarante, P. (1995). Novos sujeitos, novos direitos: o debate em torno da reforma psiquiátrica. Caderno de Saúde Pública, 11(3), 491-494.

Andrade, A. P. M. (2010). (Entre)laçamentos possíveis entre gênero e saúde mental. In: Zanello, V. \& Andrade, A. P. M. (Orgs). Saúde mental e gênero: diálogos, práticas e interdisciplinaridade (pp. 59-77). Curitiba: Appris.

Barbosa, L. B., Dimenstein, M., \& Leite, J. F. (2014). Mulheres, violência e atenção em saúde mental: questões para (re) pensar o acolhimento no cotidiano dos serviços. Avanços em Psicologia Latinoamericana, 32(2), 309-20.

Brasil, Presidência da República. (2001). Dispõe sobre a proteção e os direitos das pessoas portadoras de transtornos mentais e redireciona o modelo assistencial em saúde mental (Lei $\mathrm{n}$. 10.216/2001). Brasília, DF. Recuperado em 27 de abril de 2015 de

http://conselho.saude.gov.br/web_comissoes/cism/doc/Lei_102 16_2001.pdf

Brasil, Presidência da República. (2006). Cria mecanismos para coibir a violência doméstica e familiar contra a mulher, nos termos do $\S 8^{\circ}$ do art. 226 da Constituição Federal, da Convenção sobre a Eliminação de Todas as Formas de Discriminação contra as Mulheres e da Convenção Interamericana para Prevenir, Punir e Erradicar a Violência contra a Mulher; dispõe sobre a criação dos Juizados de Violência Doméstica e Familiar contra a Mulher; altera o Código de Processo Penal, o Código Penal e a Lei de Execução Penal; e dá outras providências (Lei n. 11.340/2006). Brasília, DF. Recuperado em 27 de abril de 2015 de 
http://www.planalto.gov.br/ccivil_03/_ato20042006/2006/lei/l11340.htm

Campos, I., \& Zanello, V. (2016). Saúde mental e gênero: o sofrimento psíquico e a invisibilidade das violências. Vivência: Revista de Antropologia, 1(48), 105-117.

Chesler, P. (2005). Women and Madness. New York: Palgrave MacMillan.

Dimenstein, M. (2013). La reforma psiquiátrica y el modelo de atención psicosocial en Brasil: en busca de cuidados continuados e integrados en salud mental. CS, (11), 43-71.

Engel, M. (2004). Psiquiatria e Feminilidade. In. M. Del Priore (Org.) História das Mulheres no Brasil (pp. 37-65). São Paulo: Contexto.

Galvão, V. A. B. M., Dimenstein, M. (2009). O protocolo de notificação da violência: entre o risco e a vulnerabilidade. Mental, 7(13), x. Recuperado em 21 de novembro de 2018, de http: // pepsic. bvsalud.org/scielo. php?script=sci_arttext\&pid=S1 679-44272009000200010\&lng=pt\&tIng=pt

Henrica, M. E., Jansen, A. F. M., Heise, L., Watts, C. H., \& GarciaMoreno, C. (2008). Intimate partner violence and women's physical and mental health in the WHO multi-country study on women's health and domestic violence: an observational study. Thelancet.com, 37, 1165-1172.

Instituto Avon (2014). Violência contra mulher: o jovem está ligado? Retirado de http://agenciapatriciagalvao.org.br/wpcontent/uploads/2014/12/pesquisaAVON-violenciajovens_versao02-12-2014.pdf

Instituto de Pesquisa Econômica Aplicada - Iepa (2014). Sistema de Indicadores de Percepção Social (SPIS): tolerância social da violência contra as mulheres. Recuperado de http://www. ipea.gov.br/portal/images/stories/PDFs/SI PS/1403 27 sips_violencia_mulheres. pdf

Maluf, S. W. (2010). Gênero, saúde, aflição: políticas públicas, ativismo e experiências sociais. In: Maluf, S. W.; Tornquist, C.S. Gênero, saúde e aflição: abordagens antropológicas (pp. 87-98). Florianópolis: Letras Contemporâneas.

Mattos, P. R., Ribeiro, I. S., Camargo, V. C. (2012). Análise dos casos notificados de violência contra a mulher. Cogitare Enfermagem. 17(4), 738-44.

Ministério da Saúde - MS. (1987). I Conferência Nacional de Saúde Mental. Recuperado de http://bvsms.saude.gov.br/bvs/publicacoes/0206cnsm_relat_fin al.pdf

Ministério da Saúde - MS. (1992). II Conferência Nacional de Saúde Mental. 
http://www. abrasme.org.br/arquivo/download?ID_ARQUIVO=3 703

Ministério da Saúde - MS. (2001). III Conferência Nacional de Saúde Mental. Recuperado de http://conselho.saude.gov.br/biblioteca/relatorios/saude_menta I. pdf

Ministério da Saúde - MS. (2004). IV Conferência Nacional de Saúde Mental. Recuperado de http://conselho.saude.gov.br/biblioteca/Relatorios/relatorio_fin al IVcnsmi cns.pdf

Narvaz, M. (2009). A (in)visibilidade do gênero na psicologia acadêmica: onde os discursos fazem(se) política. (Tese de doutorado). Instituto de Psicologia, Universidade Federal do Rio Grande do Sul, Porto Alegre, Brasil.

Organização Mundial da Saúde - OMS. (2005). WHO multi-country study on women's health and domestic violence against women: initial results on prevalence, health outcomes, and women's responses. Recuperado de http://www.who.int/gender/violence/who_multicountry_study/s ummary_report/summary_report_English $\overline{2}$.pdf

Organização Mundial da Saúde - OMS. (2010). Preventing intimate partner and sexual violence against women: taking action and generating violence. Recuperado de http://www. who.int/violence_injury_prevention/publications/vio lence/9789241564007_eng. pdf

Organização Mundial da Saúde - OMS. (2013) Responding to intimate partner violence and sexual violence against women. WHO clinical and policy guidelines. Recuperado de http://www.who.int/reproductivehealth/publications/violence/9 789241548595/en/

Pasinato, W. (2011). Avanços e obstáculos na implementação da lei 11340/2006. In C. H. Campos (Org.). Lei Maria da Penha comentada em uma perspectiva jurídico feminista (13-34). Rio de J aneiro: Lumen J uris.

Pedrosa, M. \& Zanello, V. (2017a). Reconstruindo histórias para além do diagnóstico psiquiátrico: escuta (e intervenção) de gênero como meio de empoderamento de mulheres com histórico de relações violentas. In: C. Stevens, S. Oliveira, V. Zanello, E. Silva, C. Portela (orgs.). Mulheres e violências: interseccionalidades (pp. 43-62). Brasília: Techonopolitik.

Pedrosa, M., \& Zanello, V. (2017b). (In) visibilidade da violência contra as mulheres na saúde mental. Psicologia: Teoria e Pesquisa, 32(5), 1-8.

Rose, D., Trevillion, K., Woodall, A., Morgan, C., Geder, G., Howard, L. (2011). Barriers and facilitators of disclosures of domestic 
violence by mental health service users: qualitative study. The British J ournal of Psychiatry, 198, 189-194.

Schraiber, L. B., D'Oliveira, A. F. P. L., (1999). Violência contra as mulheres: interfaces com a saúde. Interface_comunicação, Saúde, Educação, 3(5), 11-26.

Secretaria de Políticas Públicas para as Mulheres - SPM. (2004). I Plano Nacional de Políticas para as Mulheres. Recuperado de http://www.spm.gov.br/assuntos/pnpm/plano-nacionalpoliticas-mulheres.pdf

Secretaria de Políticas Públicas para as Mulheres - SPM. (2008). II Plano Nacional de Política para as Mulheres. Recuperado de http://portal.mec.gov.br/dmdocuments/planonacional_politicam ulheres. pdf

Secretaria de Políticas Públicas para as Mulheres - SPM. (2011). Política Nacional de Enfrentamento à Violência contra a Mulher. Recuperado de http://www.spm.gov.br/sobre/publicacoes/publicacoes/2011/po litica-nacional

Secretaria de Políticas Públicas para as Mulheres - SPM. (2013). III Plano Nacional de Política para as Mulheres. Recuperado de http://www.compromissoeatitude.org. br/wpcontent/uploads/20 12/08/SPM_PNPM_2013.pdf

Tenório, F. A. (2002). A reforma psiquiátrica brasileira, da década de 1980 aos dias atuais: história e conceitos. História, Ciência e Saúde, 9(1), 25-59.

Trevillion, K., Hughes, B., Feder, G., Borschmann, R., Oram, S., \& Howard, L. M. (2014). Disclosure of domestic violence in mental health settings: A qualitative meta-synthesis. International Review of Psychiatry, 26(4), 430-444.

Waiselfisz, J. J. (2015). Mapa da Violência: mortes matadas por arma de fogo. Brasília: DF Retirado de http://www.mapadaviolencia.org.br/pdf2015/mapaViolencia201 5.pdf

Zanello, V. (2014a). A saúde mental sob o viés de gênero: uma releitura gendrada da epidemiologia, da semiologia e da interpretação diagnóstica. In: Zanello, V. \& Andrade, A. P. M. (Orgs). Saúde Mental e Gênero - Diálogos, Práticas e Interdisciplinaridade (pp. 41-58). Curitiba: Appris.

Zanello, V. (2014b). Saúde mental, mulheres e conjugalidade. In Stevens, C., Oliveira, S. R., Zanello, V. Estudos Feministas e de Gênero: articulações e perspectivas. Florianópolis: Editora Mulheres. Recuperado de http://www. coloquiofeminista2014.com

Zanello, V. (2016). Saúde mental, gênero e dispositivos. In M. Dimenstein, J. Leite, J. P. Macedo, C. Dantas (orgs.) Condições 
de vida e saúde mental em contextos rurais (pp 3-14). São Paulo: Editora Intermeios.

Zanello, V., Silva, R. M. (2012). Saúde Mental, Gênero e Violência Estrutural. Bioética, 22(2), p. 267-279.

\section{Endereço para correspondência \\ Mariana Pedrosa de Medeiros}

Universidade de Brasília - UnB

Instituto de Psicologia - Departamento de Psicologia Clínica

Campus Darcy Ribeiro, Asa Norte, CEP 70910-900, Brasilia - DF, Brasil

Endereço eletrônico: mari.pmedeiros@gmail.com

\section{Valeska Zanello}

Universidade de Brasília - UnB

Instituto de Psicologia - Departamento de Psicologia Clínica

Campus Darcy Ribeiro, Asa Norte, CEP 70910-900, Brasilia - DF, Brasil

Endereço eletrônico: valeskazanello@uol.com.br

Recebido em: 24/01/2016

Reformulado em: 02/07/2017

Aceito em: 18/07/2017

\section{Notas}

* Psicóloga, Mestra e Doutoranda do Programa em Psicologia Clínica e Cultura/ UnB. Membro do grupo de pesquisa "Saúde mental e gênero". Coordernadora da Comissão das Mulheres CRP-01.

** Professora adjunta do Departamento de Psicologia Clínica da Universidade de Brasília. Orientadora do Programa de Pós-Graduação em Psicologia Clínica e Cultura/UnB. Coordenadora do grupo no CNPq "Saúde mental e gênero". Blog: https://saudementalegenero. wordpress.com/

Este artigo de revista Estudos e Pesquisas em Psicologia é licenciado sob uma Licença Creative Commons Atribuição-Não Comercial 3.0 Não Adaptada. 